\title{
Prehospital Use of Ketamine in Mountain Rescue: A Survey of Emergency Physicians of a Single-Center Alpine Helicopter-Based Emergency Service
}

\author{
Katia Vanolli ${ }^{1}$; Olivier Hugli, MD $^{2}$; David Eidenbenz ${ }^{2}$; Marc R. Suter, MD $^{3}$; Mathieu Pasquier, MD $^{2}$ \\ ${ }^{1}$ Medical School of the University of Lausanne, Lausanne, Switzerland; ${ }^{2}$ Emergency Department, Lausanne University Hospital and University of \\ Lausanne, Lausanne, Switzerland; ${ }^{3}$ Department of Anesthesia, Lausanne University Hospital and University of Lausanne, Lausanne, Switzerland
}

\begin{abstract}
Introduction-Although ketamine use in emergency medicine is widespread, studies investigating prehospital use are scarce. Our goal was to assess the self-reported modalities of ketamine use, knowledge of contraindications, and occurrence of adverse events associated with its use by physicians through a prospective online survey.

Methods-The survey was administered to physicians working for Air-Glaciers, a Swiss alpine helicopter-based emergency service, and was available between September 24 and November 23, 2018. We enrolled 39 participants (participation rate of 87\%) in our study and collected data regarding their characteristics, methods of ketamine use, knowledge of contraindications, and encountered side effects linked to the administration of ketamine. We also included a clinical scenario to investigate an analgesic strategy.

Results-Ketamine was considered safe and judged irreplaceable by most physicians. The main reason for ketamine use was acute analgesia during painful procedures, such as manipulation of femur fractures. The doses of ketamine administered with or without fentanyl ranged from 0.2 to $0.7 \mathrm{mg} \cdot \mathrm{kg}^{-1}$ intravenously. Most physicians reported using fentanyl and midazolam along with ketamine. The median dose of midazolam was 2 (interquartile range 1-2) mg for a 70-kg adult. Monitoring and oxygen administration were used infrequently. Hallucinations were the most common adverse events. Knowledge of ketamine contraindications was poor.

Conclusions - Ketamine use was reported by mountain rescue physicians to be safe and useful for acute analgesia. Most physicians use fentanyl and midazolam along with ketamine. Adverse neuropsychiatric events were rare. Knowledge regarding contraindications to the administration of ketamine should be improved.
\end{abstract}

Keywords: analgesia, contraindications, drug-related side effects and adverse reactions, HEMS

\section{Introduction}

Ketamine is widely used in prehospital medicine and mountain rescue, both in a military and civilian context. ${ }^{1-6}$ It may be used to provide analgesia or procedural sedation, as well as anesthesia induction, depending on the dose and mode of administration. ${ }^{7-10}$ Ketamine may also be used for

Corresponding author: Mathieu Pasquier, MD, Emergency Service, University Hospital Centre, BH 09, CHUV, 1011 Lausanne, Switzerland; e-mail: Mathieu.Pasquier@chuv.ch.

Submitted for publication December 2019.

Accepted for publication June 2020. its antihyperalgesic or opioid-sparing effect. It has a favorable safety profile. ${ }^{11}$ The method of administration depends not only on the indication, but also on the setting (hospital, prehospital, or austere environment) and experience of the providers (paramedics, anesthesiologists, emergency physicians). Few studies have investigated the use of ketamine in a prehospital setting. To the best of our knowledge, no studies have directly surveyed emergency physicians on its use in this setting.

Air-Glaciers is an alpine helicopter emergency medical service (HEMS) in the French-speaking part of Switzerland. The helicopter crew includes a prehospital physician specifically trained in mountain rescue, whose postgraduate 
medical training is either emergency medicine or anesthesiology. Physicians work part-time in the HEMS; the rest of their time is spent as staff physicians in hospitals or private practice. About 1700 rescue missions are performed annually, most of them for trauma during snow sports in the winter or other recreational activities in the summer. The analgesic drugs available in this HEMS are fentanyl and ketamine. Analgesia is almost always provided in the field.

The main goal of this study was to assess the methods of ketamine use by HEMS physicians through a prospective online survey. Secondary goals were to assess HEMS physicians' knowledge of contraindications and adverse events associated with the use of ketamine.

\section{Methods}

\section{ETHICS}

Because the collection of the data was anonymous and data were only accessible from the survey administrator's LimeSurvey account, we were exempted from formal approval by the institutional ethical committee (CER-VD-201800676).

\section{SURVEY DESIGN AND ELABORATION}

The online survey was conducted by using open source software (LimeSurvey GmbH, Hamburg, Germany; version 3.14) hosted on a server administered by the Lausanne University Hospital Emergency Department. The survey consisted of 65 questions divided into 5 themes. Response to all questions was mandatory to validate the survey. Before the survey was distributed, the content was tested by 4 physicians who did not belong to the target physician population.

\section{RECRUITMENT OF PARTICIPANTS}

All prehospital physicians working at the HEMS Air-Glaciers were contacted by email by the chief physician to introduce the study and the survey. They then received an invitation email with a personal link (which contained a unique code generated randomly from the list of participants) to access the survey. Only those with a link could access the survey, and the software ensured anonymization of the answers. Participants beginning the survey had the opportunity to modify their answers or complete the survey later. The use of cookies prevented a participant from submitting more than 1 questionnaire. The survey was accessible for a period of 2 mo, between September 24, 2018 and November 23, 2018. Up to 4 reminders were sent by email to doctors who had not completed or validated the questionnaire responses during this period, and the survey was then closed.

\section{SURVEY CONTENT AND DATA COLLECTION}

The data collected were included in the following main categories: the characteristics of physicians, their methods of ketamine use, their knowledge of the contraindications to ketamine use, and the side effects that they encountered after administering ketamine. In addition, we provided a clinical scenario regarding the choice and dosages of intravenous (IV) analgesic medications (fentanyl and/or ketamine) for severe acute pain from a suspected femur fracture in a $70-\mathrm{kg}$ man in a prehospital mountain setting.

The number of lifetime prehospital missions for each of the physicians was estimated by multiplying their estimated number of rescue missions by the number of prehospital years. The physicians were divided into 2 cohorts based on the median number of lifetime prehospital missions to assess a possible link between prehospital experience and methods of ketamine use. The physicians' knowledge of contraindications was assessed from the clinical practice guideline for the use of ketamine. ${ }^{10}$ We used 6-point Likert scales without a neutral position (eg, strongly disagree [1], disagree [2], slightly disagree [3], slightly agree [4], agree [5], strongly agree [6]). ${ }^{12,13}$

The full questionnaire and the comprehensive clinical scenario can be found in the Appendix (see online Appendix).

\section{STATISTICS}

Data were entered into an Excel spreadsheet (Microsoft, Redmond, WA), and the statistical analyses were conducted with Stata version 14 (Stata Corporation, College Station, TX). We present continuous data as mean \pm SD with range when normally distributed or as medians and interquartile ranges (IQRs) when non-normally distributed. Categorical data are presented as numbers and percentages. We performed comparisons by using the Student's t-test for continuous and normally distributed data and the MannWhitney 2-sample statistic for continuous and nonnormally distributed data. We used Pearson's chi-squared test and Fisher's exact test for categorical variables and the t-test to compare ordinal values. ${ }^{14}$ A 2 -tailed $P$-value of $<0.05$ was considered significant.

This article follows the CHERRIES checklist for internet surveys. ${ }^{15}$

\section{Results}

\section{DEMOGRAPHICS}

Forty-five physicians were contacted, and 39 completed the questionnaire (participation rate of $87 \%$ ). Their age was $42 \pm 9$ y (range $30-68)$, and most $(n=29,74 \%)$ were male. 
Table 1. Three most frequent indications for ketamine use reported by physicians

\begin{tabular}{llll}
\hline & $\begin{array}{l}\text { Most frequent } \\
\text { indication }(n=39) \\
n(\%)\end{array}$ & $\begin{array}{l}\text { Second most frequent } \\
\text { indication }(n=39) \\
n(\%)\end{array}$ & $\begin{array}{l}\text { Third most frequent } \\
\text { indication }(n=37) \\
n(\%)\end{array}$ \\
\hline $\begin{array}{l}\text { Acute analgesia during painful } \\
\text { procedures (eg, fracture }\end{array}$ & $38(97)$ & 0 & $1(3)$ \\
$\quad$ manipulation, casualty lifting) & & & \\
Maintenance of analgesia & 0 & $10(26)$ & $14(36)$ \\
$\begin{array}{l}\text { Opioid-sparing during acute analgesia } \\
\text { Induction of general anesthesia }\end{array}$ & 0 & $16(41)$ & $6(15)$ \\
$\begin{array}{l}\text { Procedural sedation } \\
\text { Other }\end{array}$ & 0 & $1(3)$ & $9(23)$ \\
\hline a Use if no airway access (eg, trapped patient). & $9(23)$ & $6(15)$ \\
b In addition to fentanyl if analgesia is insufficient; analgesia in an unstable patient to avoid opioid-related blood pressure drop; use in technical terrain. \\
${ }^{\mathrm{c}}$ Potentially unstable patient or patient in pain with severe injuries.
\end{tabular}

Most physicians ( $\mathrm{n}=34,87 \%$ ) were certified in prehospital emergency medicine and 19 (49\%) were board-certified anesthesiologists. The median experience in prehospital emergency medicine was 8 y (IQR 4.5-16.5; range $2-38)$. The median annual number of rescue missions was 100 (IQR 75-130; range 19-250). The median approximate total number of prehospital missions per participant was 760 (IQR 368-1825; range 110-6000).

\section{METHODS OF USE}

All physicians had used ketamine in a prehospital setting. The self-reported number of times they had used ketamine was $\leq 10$ for 25 physicians $(64 \%)$. Most physicians $(n=$ $26,67 \%$ ) reported using ketamine for most patients $(>50 \%)$ presenting with acute and severe pain. The main reported indication for ketamine use in the prehospital setting was acute analgesia during painful procedures. Other indications are summarized in Table 1 . The availability of ketamine in the prehospital arsenal was judged to be at least useful by $39(100 \%)$ and irreplaceable by $24(62 \%)$ of the participants.

\section{INJURY SITES}

We asked participants to name 5 anatomic sites of injury for which they would be the most inclined to administer ketamine. Thirty-seven $(95 \%)$ of the participants named the femur, and 29 (74\%) named this site first. The shoulder $(\mathrm{n}=17,44 \%)$ and the knee $(\mathrm{n}=16,41 \%)$ were also named by many participants.

\section{COADMINISTRATION OF KETAMINE AND FENTANYL FOR ANALGESIA}

Twenty-five participants (64\%) reported using fentanyl with ketamine for analgesia. Fifteen of 25 (60\%) reported using fentanyl with ketamine over half the time. The reported goals of coadministration were to provide deeper analgesia $(n=20,80 \%)$, to provide an opioid-sparing effect $(\mathrm{n}=12,48 \%)$, and to calm patients in case of agitation $(\mathrm{n}=$ $10,40 \%)$.

\section{INTRAMUSCULAR (IM) AND INTRANASAL (IN) KETAMINE}

A third of the participants $(n=13,33 \%)$ had administered intramuscular ketamine, mostly $(n=9,69 \%)$ for agitated or aggressive patients and for analgesia in the case of failure to establish peripheral venous access $(n=7,54 \%)$. Seven participants (18\%) reported having used intranasal (IN) ketamine, mostly in a mountain setting where it was cold and on-scene time was short $(n=5,71 \%)$ or for children $(n=4,57 \%)$.

\section{MONITORING AND OTHER INTERVENTIONS WITH THE USE OF KETAMINE}

Physicians reported use of various monitoring and other interventions with ketamine administration, as summarized in Table 2. Twenty-two participants (56\%) reported using the visual analog scale or verbal numeric rating scale (VNRS) to assess the efficacy of analgesia, and $36(92 \%)$ mentioned using clinical judgment. As a reason for not using scales, most participants (11 of 17, 65\%) referred to the inability of the patient to provide a reliable answer while under the influence of ketamine.

\section{USE IN CHILDREN}

Most physicians $(n=26,67 \%)$ reported administering ketamine proportionally less often in children than in adults, mainly due to their lack of familiarity with use in children $(n=15,58 \%)$ rather than a fear of adverse events $(n=4$, $15 \%)$. 
Table 2. Monitoring and interventions reported by physicians when using ketamine in the prehospital setting

\begin{tabular}{|c|c|c|c|c|}
\hline & $\begin{array}{l}\text { Study } \\
\text { population }(n=39) \\
n(\%)\end{array}$ & $\begin{array}{l}\text { Less prehospital } \\
\text { experience }(n=20) \\
n(\%)\end{array}$ & $\begin{array}{l}\text { More prehospital } \\
\text { experience }(n=19) \\
n(\%)\end{array}$ & $\mathrm{P}$ value \\
\hline \multicolumn{5}{|l|}{ Standard monitoring } \\
\hline 3-lead ECG & $5(13)$ & $1(5)$ & $4(21)$ & 0.134 \\
\hline Noninvasive (cuff) measure of blood pressure & $11(28)$ & $6(30)$ & $5(26)$ & 0.798 \\
\hline $\mathrm{SpO}_{2}$ & $37(95)$ & $18(90)$ & $19(100)$ & 0.157 \\
\hline Heart rate by palpation of the pulse & $24(62)$ & $12(60)$ & $12(63)$ & 0.839 \\
\hline Estimated respiratory frequency & $18(46)$ & $8(40)$ & $10(53)$ & 0.429 \\
\hline $\begin{array}{l}\text { Estimated arterial pressure by palpation of } \\
\text { peripheral pulses }\end{array}$ & $11(28)$ & $3(15)$ & $8(42)$ & 0.060 \\
\hline Other $^{\mathrm{a}}$ & $2(5)$ & & & \\
\hline Crystalloid infusion & & & & 0.544 \\
\hline Always (100\%) & $2(5)$ & 0 & $2(11)$ & \\
\hline In $>75 \%$ of cases & 0 & 0 & 0 & \\
\hline In $>50-75 \%$ of cases & $4(10)$ & $3(15)$ & $1(5)$ & \\
\hline In $>25-50 \%$ of cases & $3(8)$ & $1(5)$ & $2(11)$ & \\
\hline In $>10-25 \%$ of cases & $17(44)$ & $10(50)$ & $7(37)$ & \\
\hline In $>0-10 \%$ of cases & $8(21)$ & $4(20)$ & $4(21)$ & \\
\hline Never & $5(13)$ & $2(10)$ & $3(16)$ & \\
\hline Oxygen administration $(n=37)^{b}$ & & & & 0.949 \\
\hline Always (100\%) & $5(13)$ & $2(10)$ & $3(16)$ & \\
\hline Only in cases of desaturation or no signal & $9(23)$ & $4(20)$ & $5(28)$ & \\
\hline In $>75 \%$ of cases & $6(15)$ & $3(15)$ & $3(16)$ & \\
\hline In $>50-75 \%$ of cases & $6(15)$ & $4(20)$ & $2(11)$ & \\
\hline In $>25-50 \%$ of cases & $5(13)$ & $3(15)$ & $2(11)$ & \\
\hline In $>0-25 \%$ of cases & $6(15)$ & $3(15)$ & $3(16)$ & \\
\hline Midazolam coadministration & & & & 0.297 \\
\hline Always (100\%) & $17(44)$ & $7(35)$ & $10(53)$ & \\
\hline In $>75 \%$ of cases & $10(26)$ & $6(30)$ & $4(21)$ & \\
\hline In $>50-75 \%$ of cases & $8(21)$ & $6(30)$ & $2(11)$ & \\
\hline In $>25-50 \%$ of cases & $2(5)$ & $1(5)$ & $1(5)$ & \\
\hline In $>0-25 \%$ of cases & $2(5)$ & 0 & $2(11)$ & \\
\hline Never $(0 \%)$ & 0 & 0 & 0 & \\
\hline Midazolam median dose, $\mathrm{mg}(\mathrm{IQR})^{\mathrm{c}}$ & $2(1-2)$ & $1.5(1-2)$ & $2(1-2)$ & 0.795 \\
\hline Hypnosis used & $21(54)$ & $9(45)$ & $12(63)$ & 0.256 \\
\hline $\begin{array}{l}\text { Therapeutic communication/hypnosis } \\
\text { techniques used }(n=21)^{\mathrm{d}}\end{array}$ & & & & 0.504 \\
\hline Always (100\%) & $13(33)$ & $5(35)$ & $8(42)$ & \\
\hline In $>75 \%$ of cases & $4(10)$ & $1(5)$ & $3(16)$ & \\
\hline In $>50-75 \%$ of cases & $1(3)$ & $1(5)$ & 0 & \\
\hline In $>25-50 \%$ of cases & $2(5)$ & $1(5)$ & $1(5)$ & \\
\hline In $>0-25 \%$ of cases & $1(3)$ & $1(5)$ & 0 & \\
\hline
\end{tabular}

ECG, electrocardiogram; IQR, interquartile range

${ }^{a}$ Two participants (5\%) specified that in addition to all the other possible answers concerning monitoring, they perform noninvasive (cuff) measure of arterial pressure as well as a 3-lead ECG depending on the clinical context.

${ }^{\mathrm{b}}$ One participant specified that oxygen administration would depend on the injury assessment; one other would give oxygen except when the airway was not accessible.

${ }^{c}$ One physician in the more experienced group used $1 \mathrm{mg}$ midazolam for each $20 \mathrm{mg}$ of ketamine; considered as missing data.

${ }^{\mathrm{d}}$ Reported examples included reassuring, explaining clearly and calmly the effects and suggesting positive thoughts before administering ketamine $(\mathrm{n}=18)$, maintaining physical and/or verbal contact during sedation $(\mathrm{n}=3)$, hypnosis $(\mathrm{n}=1)$, and advising family not to stimulate the patient after administration $(n=1)$. Perceived benefits of these techniques were a reduction of adverse neuropsychiatric side effects, such as "bad trip," anxiety, hallucinations, or agitation, as well as a better control of analgesia or sedation. The main disadvantages were that these methods were time-consuming and not always possible depending on weather and possibly a noisy environment. 
Table 3. Contraindications to ketamine administration reported by the physicians and according to the literature

\begin{tabular}{|c|c|c|c|}
\hline & \multicolumn{3}{|c|}{ Reported answers } \\
\hline & \multicolumn{2}{|c|}{ Contraindicated } & \multirow{2}{*}{$\begin{array}{l}\text { Not contraindicated } \\
n(\%)\end{array}$} \\
\hline & $\begin{array}{l}\text { Absolute } \\
n(\%)\end{array}$ & $\begin{array}{l}\text { Relative } \\
n(\%)\end{array}$ & \\
\hline \multicolumn{4}{|l|}{ Absolute contraindication } \\
\hline Unstable schizophrenia & $24(62)$ & $12(31)$ & $3(8)$ \\
\hline Children $<3$ mo old & $15(38)$ & $15(38)$ & $9(23)$ \\
\hline Stable schizophrenia & $4(10)$ & $25(64)$ & $10(26)$ \\
\hline \multicolumn{4}{|l|}{ Relative contraindication } \\
\hline Increased intracranial pressure & $12(31)$ & $23(59)$ & $4(10)$ \\
\hline Preeclampsia or eclampsia & $24(62)$ & $9(23)$ & $6(15)$ \\
\hline Uncontrolled arterial hypertension & $3(8)$ & $23(59)$ & $13(33)$ \\
\hline Poorly controlled hyperthyroidism & $7(18)$ & $15(38)$ & $17(44)$ \\
\hline Patients requiring endoscopy & 0 & $10(26)$ & $29(74)$ \\
\hline Asthma & $1(3)$ & $5(13)$ & $33(85)$ \\
\hline \multicolumn{4}{|l|}{ Not contraindicated } \\
\hline Severe head trauma & $6(15)$ & $24(62)$ & $9(23)$ \\
\hline Mood disorders & $2(5)$ & $25(64)$ & $12(31)$ \\
\hline Pregnancy & $11(28)$ & $13(33)$ & $15(38)$ \\
\hline Noisy environment & $\mathbf{0}$ & $23(59)$ & $16(41)$ \\
\hline History of stroke & $3(8)$ & $18(46)$ & $18(46)$ \\
\hline Agitated patients & $1(3)$ & $16(41)$ & $22(56)$ \\
\hline Children $<5$ y old & $\mathbf{0}$ & $12(31)$ & $27(69)$ \\
\hline Ambient temperature $<0^{\circ} \mathrm{C}$ & $\mathbf{0}$ & $5(13)$ & $34(87)$ \\
\hline
\end{tabular}

Results are expressed as numbers (\%). In italics: reported answers corresponding to the guideline in the literature. In bold: reported as not contraindicated although absolutely contraindicated or contraindications reported as absolute although not contraindicated.

\section{CLINICAL SCENARIO}

Regarding the clinical scenario proposed (see online Appendix), 14 participants (36\%) chose a combination of fentanyl $(104 \pm 24 \mu \mathrm{g})$ and ketamine $(39 \pm 25 \mathrm{mg})$. Thirteen $(33 \%)$ chose ketamine $(35 \pm 14 \mathrm{mg})$ alone and $12(31 \%)$ chose fentanyl $(90 \pm 31 \mu \mathrm{g})$ alone. In the case of insufficient analgesia after the initial bolus, all participants chose titration with additional boluses of fentanyl $(57 \pm 18 \mu \mathrm{g})$ or ketamine $(19 \pm 6 \mathrm{mg})$.

\section{KNOWLEDGE OF THE CONTRAINDICATIONS TO KETAMINE}

The answers of physicians regarding their knowledge about the contraindications to ketamine are summarized in Table $3 .{ }^{10}$ Ten physicians (26\%) reported that ketamine is not contraindicated in stable schizophrenia, and $9(23 \%)$ reported that ketamine is not contraindicated in children $<3$ mo old. Both factors are described as absolute contraindications in the guideline. Eleven physicians (28\%) reported ketamine as absolutely contraindicated in pregnancy and $6(15 \%)$ as absolutely contraindicated in severe head trauma. According to the guideline, neither of these factors contraindicates the use of ketamine.

\section{ADVERSE EVENTS}

A number of adverse events were reported (Table 4). The frequency of adverse events was not related to the lifetime number of prehospital missions. Hallucinations were the most common adverse event, being reported by 28 participants $(72 \%)$, and were most often visual $(n=28,100 \%)$ or auditory $(n=16,57 \%)$. Methods used to avoid hallucinations were the coadministration of midazolam for 10 physicians $(36 \%)$, reassurance of the patient for $3(11 \%)$, and use of hypnosis for 1 . Fourteen participants $(50 \%)$ did not use any particular strategy.

According to physicians' observations $(n=36)$, patients experienced mostly positive neuropsychiatric side effects. Twenty-three physicians (64\%) responded that patients' experience was generally positive $(\mathrm{n}=13,36 \%)$, positive $(n=9,25 \%)$, or always positive $(n=1)$. Despite the reported adverse events, all participants considered ketamine to be generally rather safe $(n=7,18 \%)$, safe $(n=29,74 \%)$, or totally safe $(n=3,8 \%)$. The majority of participants $(n=35,90 \%)$ also considered opiates to be rather safe, safe, or totally safe. Participants preferred to administer ketamine rather than fentanyl mainly because ketamine produces less respiratory depression $(\mathrm{n}=34,87 \%)$, allows for deeper analgesia $(\mathrm{n}=$ $32,82 \%)$, and has a superior safety profile $(\mathrm{n}=28,72 \%)$. 
Table 4. Reported side effects encountered at least once in prehospital career by a participant after ketamine administration in prehospital

\begin{tabular}{|c|c|c|c|c|}
\hline $\begin{array}{l}\text { Side effects, } \\
n(\%)\end{array}$ & $\begin{array}{l}\text { Study population } \\
(n=39) \\
n(\%)\end{array}$ & $\begin{array}{l}\text { Less prehospital } \\
\text { experience } \\
n(\%)\end{array}$ & $\begin{array}{l}\text { More prehospital } \\
\text { experience } \\
n(\%)\end{array}$ & $\mathrm{P}$ value \\
\hline Hallucinations & $28(72)$ & $14(70)$ & $14(74)$ & 0.798 \\
\hline Agitation & $19(49)$ & $8(40)$ & $11(58)$ & 0.264 \\
\hline Hypersalivation & $16(41)$ & $8(40)$ & $8(42)$ & 0.894 \\
\hline Tachycardia & $15(38)$ & $7(35)$ & $8(42)$ & 0.648 \\
\hline Arterial hypertension & $14(36)$ & $5(25)$ & $9(47)$ & 0.146 \\
\hline Anxiety & $14(36)$ & $7(35)$ & $7(37)$ & 0.905 \\
\hline Bradypnea & $10(26)$ & $4(20)$ & $6(32)$ & 0.408 \\
\hline Desaturation & $1026)$ & $6(30)$ & $4(21)$ & 0.522 \\
\hline Emergence reaction & $9(23)$ & $4(51)$ & $5(26)$ & 0.640 \\
\hline Respiratory depression & $5(13)$ & $2(10)$ & $3(16)$ & 0.589 \\
\hline Hypertonia & $5(13)$ & $2(10)$ & $3(16)$ & 0.589 \\
\hline Apnea & $4(10)$ & $1(5)$ & $3(16)$ & 0.267 \\
\hline Nausea/Vomiting & $4(10)$ & $3(15)$ & $1(5)$ & 0.316 \\
\hline Stereotypy (repetitive behavior) & $3(8)$ & $1(5)$ & $2(11)$ & 0.517 \\
\hline Clonus & $2(5)$ & $1(5)$ & $1(5)$ & 0.970 \\
\hline Hiccups & $2(5)$ & 0 & $2(11)$ & 0.136 \\
\hline Anaphylactic reaction & $2(5)$ & 0 & $2(11)$ & 0.136 \\
\hline Airway obstruction & $1(3)$ & 0 & $1(5)$ & 0.299 \\
\hline Laryngospasm & $1(3)$ & 0 & $1(5)$ & 0.299 \\
\hline
\end{tabular}

\section{Discussion}

\section{METHODS OF USE}

All physicians in our study had used ketamine in the prehospital setting, and they all considered ketamine to be useful or irreplaceable. A study on paramedics reported that most (94\%) felt comfortable with ketamine administration; $95 \%$ would use it again in an analogous situation. ${ }^{16} \mathrm{~A}$ smaller survey of hospital emergency physicians showed a satisfaction rate of $72 \%$ after ketamine use for analgesia and that $96 \%$ would use ketamine again. ${ }^{17}$ In our study, ketamine was mostly used by emergency physicians to manage acute pain. This usage was also reported to be the case in a hospital setting. ${ }^{18}$ The most frequently reported indication for ketamine was pain relief, especially to decrease the pain of fracture manipulation, which is not surprising because long-bone fractures induce severe pain. ${ }^{19}$ The most frequent reason for use of ketamine instead of or with fentanyl is that ketamine provides deeper analgesia. This response is consistent with a retrospective study conducted in the same HEMS that found a positive correlation between the severity of pain and ketamine administration. ${ }^{20}$ However, a recent report did not show a significantly greater reduction in the numerical rating scale with ketamine than with morphine. ${ }^{21}$ The other reported reason was that participants considered ketamine to have a better safety profile than fentanyl. A better safety profile in favor of ketamine has not been clearly established in the literature. ${ }^{21}$
A survey of emergency physicians revealed that $96 \%$ of participants considered ketamine to be underused for analgesia in adults. Most of the respondents saw the possible emergence reactions as a reason for this underuse. ${ }^{17}$ Another survey of emergency physicians revealed that the most feared side effects were psychedelic effects and hallucinations. ${ }^{18}$ In the present study, we defined emergence reactions as vivid visual hallucinations or dreaming occurring during the recovery phase that the patient can experience as pleasant or unpleasant. ${ }^{22-24}$ Twenty-three percent of physicians encountered emergence reactions. Previous studies reported that 0 to $76 \%$ of patients experience an emergence reaction with ketamine. The definition of these reactions varies between studies, but unpleasant emergence reactions seem to be uncommon. ${ }^{3,22,24,25} \mathrm{Hal}-$ lucinations were frequently encountered in our study, and physicians mostly reported patients' experiences of neuropsychiatric side effects to be positive.

The coadministration of midazolam is supported by guidelines for reducing emergence reactions after procedural sedation. ${ }^{10,26,27} \mathrm{We}$ found that, as in other prehospital studies, midazolam was frequently coadministered with ketamine. ${ }^{28-31}$ The use of empathy (reassurance, addressing the patient by name, informing the patient about the dissociative effects and the ongoing procedure to reduce emergence reactions and pain) was another frequently proposed intervention. Many participants reported using therapeutic communications such as guiding patients to 
picture pleasant dreams, with the goal of reducing the occurrence of neuropsychiatric side effects. ${ }^{10,32,33} \mathrm{~A}$ recent study suggested that administering ketamine as a 15-min infusion rather than a bolus reduces emergence reactions, although this strategy is usually not practical in a prehospital setting. ${ }^{34}$

The favorable safety profile, combined with considerations of the difficult terrain and austere conditions, may partially explain the low reported rate of monitoring when administrating ketamine. In spite of recent guidelines that no longer recommend the administration of oxygen, even for procedural sedation, we found that a high proportion of physicians administered oxygen to patients receiving ketamine. Studies on the adverse effects of ketamine showed that cardiorespiratory adverse events were rare. $^{7,10,35}$

A study on the epidemiology of pain in the prehospital setting - which did not include use of ketamine-reported the availability of initial and final VNRS pain scores in 93,613 of $108,853(86 \%)$ patients. ${ }^{36}$ In our study, only $56 \%$ of physicians reported using a visual analog scale or VNRS to assess pain. Pain perception is complex, and self-reporting with a unidimensional scale may not be a reliable predictor of the patient's wish for analgesia. ${ }^{37}$ Pain scales in patients receiving ketamine may be invalid due to ketamine's dissociative effects (dissociation may be defined as a trancelike state, characterized by catalepsy, catatonia, analgesia, and amnesia ${ }^{38}$ ), a point that many participants in our study underlined.

Only a minority of physicians had used the IM or IN routes for ketamine. A retrospective study conducted $6 \mathrm{y}$ prior in the same HEMS reported no use of IM or IN ketamine. ${ }^{28}$ Although IM use in pediatrics has been well demonstrated with a good efficacy and safety profile, ${ }^{26,39}$ IV use is still preferred in adults because it allows rapid administration of midazolam in the case of unpleasant neuropsychiatric effects. IM administration is associated with more vomiting and a longer recovery time. ${ }^{26}$ A recent randomized clinical trial in children showed that IN ketamine was noninferior to IN fentanyl for pain relief for acute extremity injuries. ${ }^{40}$ Our participants emphasized the advantages of IN administration in mountain rescue but also reported that the unpredictability of the IN route was an obstacle to its widespread use.

\section{CLINICAL SCENARIO}

The ketamine dose for treating acute pain was in the upper range of what was recommended in a systematic review of ketamine analgesia in a prehospital setting $(0.1-0.5$ $\left.\mathrm{mg} \cdot \mathrm{kg}^{-1} \mathrm{IV}\right){ }^{3}$ We found a relatively wide dose range for ketamine with or without fentanyl $\left(0.2-0.7 \mathrm{mg} \cdot \mathrm{kg}^{-1} \mathrm{IV}\right.$, which equals $14-49 \mathrm{mg}$ IV for a $70-\mathrm{kg}$ person). These interphysician variations probably reflect the fact that our HEMS does not have a dosing protocol for ketamine, and thus the dose is left to the discretion of the physician. We did not find a decrease in the dose of fentanyl when administered with ketamine in our clinical scenario. Combining fentanyl and ketamine may augment the effect of analgesia and allows for the reduction of the opiate dose. However, some studies have found an increased incidence of minor events when opiates and ketamine are combined. ${ }^{24,30,41-44}$

\section{KNOWLEDGE OF THE CONTRAINDICATIONS TO KETAMINE}

Knowledge of ketamine contraindications was poor. Intracranial hypertension and traumatic brain injury were previously considered to be contraindications to the use of ketamine. Recent systematic reviews failed to show a significant increase of intracranial pressure with ketamine, including in patients with traumatic brain injury. ${ }^{45-47}$ Many physicians thought that stable schizophrenia and age of $<3$ mo were not contraindications, although they are absolute contraindications. ${ }^{48-50}$ Many physicians mentioned pregnancy as an absolute contraindication, although it was not specified in the clinical practice guideline used in our study. ${ }^{10}$ There is a paucity of data regarding the use of ketamine in pregnancy and no human data on teratogenicity. ${ }^{51}$

\section{LIMITATIONS}

Our study has some limitations. It was a single-center study with a limited sample size (39 participants) that might not reflect the use of ketamine in other centers. All of our data were self-reported and based on opinions made by physicians, and we had no way of verifying the accuracy of the data. We do not know whether the nonresponders had different patterns of using ketamine than the respondents did. The focus on ketamine may have led participants to overestimate their use of ketamine and may not have reflected actual practice, especially in the clinical scenario. We proposed a single clinical scenario, and it may not be possible to extrapolate the responses to another scenario. Only racemic ketamine was available in our HEMS. Studies showed that the racemic mixture may cause more neuropsychiatric adverse events and have less analgesic potency than Sketamine. $^{52,53}$ These effects could lead to bias when comparing doses and adverse events from studies that use Sketamine. We did not ask physicians to report whether adverse events occurred with ketamine alone or when ketamine was used with other drugs, such as fentanyl or midazolam. We do not know whether our data accurately portray the adverse event profile of ketamine. 


\section{Conclusions}

In this prospective survey, the physicians of an alpine HEMS reported high satisfaction regarding the safety and utility of ketamine for analgesia in the prehospital setting. The main reason for ketamine use was acute analgesia during painful procedures, such as manipulation of femur fractures. Most physicians use fentanyl and midazolam along with ketamine; few had experience in the use of IN ketamine. Adverse neuropsychiatric events were seldom reported. We found a lack of knowledge regarding contraindications to the administration of ketamine, which may be improved through targeted educational efforts.

Acknowledgments: We thank the physicians of the Air-Glaciers HEMS for their participation in our survey; Grégoire Zen Ruffinen, chief physician at Air-Glaciers, for his support in the distribution of the survey; and David Caillet-Bois, data manager at the CHUV, for his assistance in designing the web survey.

Author Contributions: Study concept and design (KV, MP); acquisition of the data and literature search (KV, MP); analysis of the data $(\mathrm{KV}, \mathrm{OH}$, $\mathrm{MP})$; drafting of the manuscript ( $\mathrm{KV}, \mathrm{OH}, \mathrm{MP})$; critical revision of the manuscript (KV, OH, MRS, MP, DE); approval of final manuscript (KV, $\mathrm{MP}, \mathrm{OH}, \mathrm{DE}, \mathrm{MRS})$.

Financial/Material Support: None.

Disclosures: None.

\section{Supplementary data}

Supplementary material associated with this article can be found in the online version at https://doi.org/10.1016/j. wem.2020.06.004.

\section{References}

1. Russell KW, Scaife CL, Weber DC, Windsor JS, Wheeler AR, Smith WR, et al. Wilderness Medical Society practice guidelines for the treatment of acute pain in remote environments: 2014 update. Wilderness Environ Med. 2014;25(4 Suppl):S96-104.

2. Wedmore IS, Johnson T, Czarnik J, Hendrix S. Pain management in the wilderness and operational setting. Emerg Med Clin North Am. 2005;23(2):585-601.

3. Jennings PA, Cameron P, Bernard S. Ketamine as an analgesic in the pre-hospital setting: a systematic review. Acta Anaesthesiol Scand. 2011;55(6):638-43.

4. Zietlow J, Berns K, Jenkins D, Zietlow S. Prehospital use of ketamine: effectiveness in critically ill and injured patients. Mil Med. 2019;184(Suppl 1):542-4.

5. Ellerton J, Paal P, Brugger H. Prehospital use of ketamine in mountain rescue. Emerg Med J. 2009;26(10):760-1.

6. Marland S, Ellerton J, Andolfatto G, Strapazzon G, Thomassen O, Brandner B, et al. Ketamine: use in anesthesia. CNS Neurosci Ther. 2013;19(6):381-9.

7. Lee EN, Lee JH. The effects of low-dose ketamine on acute pain in an emergency setting: a systematic review and metaanalysis. PLoS One. 2016;11(10), e0165461.
8. Pourmand A, Mazer-Amirshahi M, Royall C, Alhawas R, Shesser R. Low dose ketamine use in the emergency department, a new direction in pain management. Am J Emerg Med. 2017;35(6):918-21.

9. Godwin SA, Burton JH, Gerardo CJ, Hatten BW, Mace SE, Silvers SM, et al. Clinical policy: procedural sedation and analgesia in the emergency department. Ann Emerg Med. 2014;63(2):247-58.

10. Green SM, Roback MG, Kennedy RM, Krauss B. Clinical practice guideline for emergency department ketamine dissociative sedation: 2011 update. Ann Emerg Med. 2011;57(5):449-61.

11. Visser E, Schug SA. The role of ketamine in pain management. Biomed Pharmacother. 2006;60(7):341-8.

12. Likert R. A technique for the measurement of attitudes. Arch Psychol. 1932;22(140):55.

13. Sullivan GM, Artino Jr AR. Analyzing and interpreting data from Likert-type scales. J Grad Med Educ. 2013;5(4):541-2.

14. de Winter JF, Dodou D. Five-point Likert items: t test versus Mann-Whitney-Wilcoxon. Pract Assess Res Eval. 2010;15(1):11.

15. Eysenbach G. Improving the quality of web surveys: the checklist for reporting results of internet e-surveys (CHERRIES). J Med Internet Res. 2004;6(3):e34.

16. Buckland DM, Crowe RP, Cash RE, Gondek S, Maluso P, Sirajuddin S, et al. Ketamine in the prehospital environment: a national survey of paramedics in the United States. Prehosp Disaster Med. 2018;33(1):23-8.

17. Richards JR, Rockford RE. Low-dose ketamine analgesia: patient and physician experience in the ED. Am J Emerg Med. 2013;31(2):390-4.

18. Martinez V, Derivaux B, Beloeil H. Ketamine for pain management in France, an observational survey. Anaesth Crit Care Pain Med. 2015;34(6):357-61.

19. Siddiqui A, Belland L, Rivera-Reyes L, Handel D, Yadav K, Heard K, et al. A multicenter evaluation of emergency department pain care across different types of fractures. Pain Med. 2017;18(1):41-8.

20. Eidenbenz D, Taffé P, Hugli O, Albrecht E, Pasquier M. A two-year retrospective review of the determinants of prehospital analgesia administration by alpine helicopter emergency medical physicians to patients with isolated limb injury. Anaesthesia. 2016;71(7):779-87.

21. Sobieraj DM, Martinez BK, Miao B, Cicero MX, Kamin RA, Hernandez AV, et al. Comparative effectiveness of analgesics to reduce acute pain in the prehospital setting. Prehosp Emerg Care. 2020;24(2):163-74.

22. Green SM, Li J. Ketamine in adults what emergency physicians need to know about patient selection and emergence reactions. Acad Emerg Med. 2000;7(3):278-81.

23. Powers 3rd AR, Gancsos MG, Finn ES, Morgan PT, Corlett PR. Ketamine-induced hallucinations. Psychopathology. 2015;48(6):376-85.

24. Strayer RJ, Nelson LS. Adverse events associated with ketamine for procedural sedation in adults. Am J Emerg Med. 2008;26(9):985-1028.

25. Erstad BL, Patanwala AE. Ketamine for analgosedation in critically ill patients. J Crit Care. 2016;35:145-9. 
26. Sener S, Eken C, Schultz CH, Serinken M, Ozsarac M. Ketamine with and without midazolam for emergency department sedation in adults: a randomized controlled trial. Ann Emerg Med. 2011;57(2):109-14.

27. Akhlaghi N, Payandemehr P, Yaseri M, Akhlaghi AA, Abdolrazaghnejad A. Premedication with midazolam or haloperidol to prevent recovery agitation in adults undergoing procedural sedation with ketamine: a randomized double-blind clinical trial. Ann Emerg Med. 2019;73(5):462-9.

28. Pasquier M, Eidenbenz D, Dami F, Zen Ruffinen G, Hugli O. Pain management strategies and time spent on scene for prehospital analgesia provision in an alpine environment: a retrospective study. Emerg Med Open Access. 2017;7(4):1000360.

29. Bredmose PP, Lockey DJ, Grier G, Watts B, Davies G. Prehospital use of ketamine for analgesia and procedural sedation. Emerg Med J. 2009;26(1):62-4.

30. Oberholzer N, Kaserer A, Albrecht R, Seifert B, Tissi M, Spahn D, et al. Factors influencing quality of pain management in a physician staffed helicopter emergency medical service. Anesth Analg. 2017;125(1):200-9.

31. Chesters A, Webb T. Ketamine for procedural sedation by a doctor-paramedic prehospital care team. Eur J Emerg Med. 2015;22(6):401-6.

32. Cheong S, Lee K, Lim S, Cho K, Kim M, Ko M, et al. The effect of suggestion on unpleasant dreams induced by ketamine administration. Anesth Analg. 2011;112(5):1082-5.

33. Sklar GS, Zukin SR, Reilly TA. Adverse reactions to ketamine anaesthesia. Anaesthesia. 1981;36(2):183-7.

34. Motov S, Mai M, Pushkar I, Likourezos A, Drapkin J, Yasavolian M, et al. A prospective randomized, doubledummy trial comparing IV push low dose ketamine to short infusion of low dose ketamine for treatment of pain in the ED. Am J Emerg Med. 2017;35(8):1095-100.

35. Bellolio MF, Gilani WI, Barrionuevo P, Murad MH, Erwin PJ, Anderson JR, et al. Incidence of adverse events in adults undergoing procedural sedation in the emergency department: a systematic review and meta-analysis. Acad Emerg Med. 2016;23(2):119-34.

36. Jennings PA, Cameron P, Bernard S. Epidemiology of prehospital pain: an opportunity for improvement. Emerg Med J. 2011;28(6):530-1.

37. Green SM, Krauss BS. The numeric scoring of pain: this practice rates a zero out of ten. Ann Emerg Med. 2016;67(5): 573-5.

38. Absalom A, Menon DK, Adapa R. Dissociative anesthetics. In: Stolerman IP, Price LH, eds. Encyclopedia of Psychopharmacology. 2nd ed. Heidelberg, Germany: Springer-Verlag; 2014:522-6.

39. Roback MG, Wathen JE, MacKenzie T, Bajaj L. A randomized, controlled trial of i.v. versus i.m. ketamine for sedation of pediatric patients receiving emergency department orthopedic procedures. Ann Emerg Med. 2006;48(5):605-12.
40. Frey TM, Florin TA, Caruso M, Zhang N, Zhang Y, Mittiga MR. Effect of intranasal ketamine vs fentanyl on pain reduction for extremity injuries in children: the PRIME randomized clinical trial. JAMA Pediatr. 2019;173(2):140-6.

41. Beaudoin FL, Lin C, Guan W, Merchant RC. Low-dose ketamine improves pain relief in patients receiving intravenous opioids for acute pain in the emergency department: results of a randomized, double-blind, clinical trial. Acad Emerg Med. 2014;21(11):1193-202.

42. Galinski M, Dolveck F, Combes X, Limoges V, Smaïl N, Pommier V, et al. Management of severe acute pain in emergency settings: ketamine reduces morphine consumption. Am J Emerg Med. 2007;25(4):385-90.

43. Jennings PA, Cameron P, Bernard S, Walker T, Jolley D, Fitzgerald M, et al. Morphine and ketamine is superior to morphine alone for out-of-hospital trauma analgesia: a randomized controlled trial. Ann Emerg Med. 2012;59(6):497-503.

44. Johansson P, Kongstad P, Johansson A. The effect of combined treatment with morphine sulphate and low-dose ketamine in a prehospital setting. Scand J Trauma Resusc Emerg Med. 2009;17:61.

45. Loflin R, Koyfman A. When used for sedation, does ketamine increase intracranial pressure more than fentanyl or sufentanil? Ann Emerg Med. 2015;65(1):55-6.

46. Cohen L, Athaide V, Wickham ME, Doyle-Waters MM, Rose NGW, Hohl CM. The effect of ketamine on intracranial and cerebral perfusion pressure and health outcomes: a systematic review. Ann Emerg Med. 2015;65(1):43-51.

47. Zeiler FA, Teitelbaum J, West M, Gillman LM. The ketamine effect on ICP in traumatic brain injury. Neurocrit Care. 2014;21(1):163-73.

48. Malhotra AK, Pinals DA, Adler CM, Elman I, Clifton A, Pickar D, et al. Ketamine-induced exacerbation of psychotic symptoms and cognitive impairment in neuroleptic-free schizophrenics. Neuropsychopharmacology. 1997;17(3):141-50.

49. Lahti AC, Weiler MA, Tamara Michaelidis BA, Parwani A, Tamminga CA. Effects of ketamine in normal and schizophrenic volunteers. Neuropsychopharmacology. 2001;25(4):455-67.

50. Le Cong M, Gynther B, Hunter E, Schuller P. Ketamine sedation for patients with acute agitation and psychiatric illness requiring aeromedical retrieval. Emerg Med J. 2012;29(4): 335-7.

51. Neuman G, Koren G. Safety of procedural sedation in pregnancy. J Obstet Gynaecol Can. 2013;35(2):168-73.

52. Pfenninger EG, Durieux ME, Himmelseher S. Cognitive impairment after small-dose ketamine isomers in comparison to equianalgesic racemic ketamine in human volunteers. Anesthesiology. 2002;96(2):357-66.

53. Peltoniemi MA, Hagelberg NM, Olkkola KT, Saari TI. Ketamine: a review of clinical pharmacokinetics and pharmacodynamics in anesthesia and pain therapy. Clin Pharmacokinet. 2016;55(9):1059-77. 